\title{
EL FEMICIDIO EN ARgENTINA (2014-2017): UN ANÁlisis DESDE LA CRIMINOLOGÍA CAUTELAR
}

\section{Esther Pineda $\mathbf{G}^{1}$}

Resumen: El artículo hace un recorrido por el tradicional abordaje criminológico de los procesos de victimización de las mujeres hasta la emergencia del femicidio como categoría de análisis fenomenológico y penal. Se abordan el proceso de tipificación del delito de femicidio en América Latina y en Argentina, el empleo de las técnicas de neutralización por parte de los distintos actores e instituciones sociales ante la ocurrencia del referido crimen, y la necesidad de un análisis desde la criminología cautelar del femicidio en la sociedad argentina, con base en las estadísticas del Registro Nacional de Femicidios correspondiente a los años 2014 a 2017.

Palabras clave: Argentina, Criminología cautelar, Femicidio, Técnicas de neutralización.

Abstract: The article takes a tour of the traditional criminological approach to the processes of victimization of women until the emergence of femicide as a category of phenomenological and criminal analysis. It deals with the process of typification of the crime of

1 Socióloga, Magister Scientiarum en Estudios de la Mujer, Doctora y Postdoctora en Ciencias Sociales egresada de la Universidad Central de Venezuela. Correo electrónico: estherpinedag@gmail.com 
femicide in Latin America and Argentina, the use of techniques of neutralization by the different social actors and institutions before the occurrence of the aforementioned crime; and the need for an analysis from the prudential criminology of femicide in Argentine society, based on statistics from the National Registry of Femicides for the years 2014 to 2017.

Key words: Argentina, Femicide, Neutralization techniques, Prudential criminology.

Resum: L'article fa un recorregut pel tradicional abordatge criminològic dels processos de victimització de les dones fins a l'emergència del feminicidi com a categoria d'anàlisi fenomenològic i penal. S'hi aborden el procés de tipificació del delit de feminicidi a l'Amèrica Llatina i Argentina, l'ús de les tècniques de neutralització per part dels diferents actors $\mathrm{i}$ institucions socials davant l'ocurrència de l'esmentat crim i la necessitat d'una anàlisi des de la criminologia cautelar del feminicidi en la societat argentina, basat en les estadístiques del Registre Nacional de Feminicidis corresponent als anys 2014 a 2017.

Paraules clau: Argentina, Criminologia cautelar, Feminicidi, Tècniques de neutralització.

\section{Introducción}

El femicidio puede considerarse la forma extrema de violencia contra la mujer, la cual se caracteriza y diferencia del homicidio por sus motivaciones sexistas y misóginas, así como, por su comisión en el contexto de desigualdades por razones de género y relaciones de poder, dominación y dependencia.

Este tipo de crímenes comenzaron a ser tipificados en América Latina durante la última década, sin embargo, los Estados se han 
conformado con la aplicación de penas ejemplificadoras, obviando su prevención. Aunado a ello, los victimarios, la población en general, los medios de comunicación y los operadores de justicia ante la ocurrencia de estos delitos han puesto en práctica distintas técnicas de neutralización, las cuales funcionan como acciones y narrativas de justificación, al mismo tiempo que favorecen su ocurrencia en un marco de impunidad.

Estos hechos en su conjunto han impelido la erradicación del fenómeno, incluso es posible considerar que han influido en su incremento; así lo evidencian algunas estadísticas del Registro Nacional de Femicidios de la Justicia Argentina, las cuales en este trabajo son analizadas desde la perspectiva de la criminología cautelar, con el fin de proporcionar insumos que propicien la comprensión del delito y la desaceleración de la victimación de las mujeres mediante la implementación de acciones preventivas.

\section{La emergencia del femicidio como categoría fenomenológica y penal}

Los procesos de victimación generizada y sexualizada de las mujeres han estado presente y se han hecho manifiestas en las diferentes etapas del proceso histórico social; estas se expresan principalmente en múltiples formas de violencia, la violación y el asesinato de una mujer por el hecho de ser mujer, en el contexto de las desigualdades y relaciones de poder, dominación y dependencia; pese a ello, esta problemática ha sido continuamente desatendida desde la criminología.

De acuerdo a una revisión de la literatura criminológica hecha por González (2014), hasta 1960 los homicidios de las mujeres habían sido analizados únicamente bajo el enfoque de las teorías criminológicas clásicas, los cuales explicaban el homicidio de mujeres en el contexto de pareja como una consecuencia de las condiciones económicas de pobreza, las cuales podían incidir en las tasas de homicidios de mujeres al incrementar la desorganización social (C.R. 
Shaw y H.D. McKay), al aumentar el estrés (R.K. Merton), o al propiciar oportunidades para delinquir (L.E. Cohen y M. Felson). Esta perspectiva materialista que coloca la atención en la dimensión económica e invisibiliza las múltiples formas de desigualdad y relaciones de poder que subyacen en la violencia por razones de género y el femicidio continúa siendo reproducida aún en la actualidad por pensadoras como Rita Segato quien, en una entrevista ha afirmado:

"La vida se ha vuelto inmensamente precaria, y el hombre, que por su mandato de masculinidad, tiene la obligación de ser fuerte, de ser el potente, no puede más y tiene muchas dificultades para poder serlo. $Y$ esas dificultades no tienen que ver como dicen por ahí, porque está afectado por el empoderamiento de las mujeres, que es un argumento que se viene utilizando mucho, que las mujeres se han empoderado y que los hombres se han debilitado por ello y por lo tanto reaccionan así... No. Lo que debilita a los hombres, lo que los precariza y los transforma en sujetos impotentes es la falta de empleo, la inseguridad en el empleo cuando lo tienen, la precariedad de todos los vínculos, el desarraigo de varias formas, el desarraigo de un medio comunitario, familiar, local... en fin, el mundo se mueve de una manera que no pueden controlar y los deja en una situación de precariedad, pero no como consecuencia del empoderamiento de las mujeres, sino como una consecuencia de la precarización de la vida, de la economía, de no poder educarse más, leer más, tener acceso a diversas formas de bienestar" (Segato, 2017, sp.).

Por su parte, los crímenes cometidos contra las mujeres como la violencia de género, la violación y los homicidios en el contexto de relaciones de pareja -considerados por la criminología como crímenes pasionales- también fueron abordados desde la perspectiva victimológica. Al respecto señala Peters (1990) que autores como 
Etienne De Greef trataron de explicarlos a través de la interacción particular entre el autor y la víctima, centrándose en el papel activo o pasivo de la víctima en cuanto a la génesis del delito y distinguiendo entre: 1) Victimas por azar. 2) Victimas con un comportamiento tan problemático como los autores. 3) Victimas por no haber evitado el delito (por falta de cuidado o de atención). 4) Victimas por descuidar las medidas de prevención, creando así causas situacionales del delito.

La victimología partía entonces del principio de corresponsabilidad y autorresponsabilidad de la víctima, concentrándose en cuestionar en qué medida la víctima había contribuido a la perpetración del delito (Peters, 1988), y, en otras ocasiones, según Cuarezma (1996) a considerarla la verdadera causante del delito. Esta perspectiva sería resumida en el concepto victim precipitation, introducido inicialmente por Martin Wolfgang, sin embargo, dicho enfoque prejuiciado, culpabilizador y revictimizador de las víctimas, así como, su intento de legitimación académica y científica no fue recibido de forma pasiva; por el contrario, "dio lugar a reacciones violentas por parte de círculos feministas y estigmatizó a la victimología como «el arte de censura de la víctima» (Peters, 1988, p. 111).

Empero, aunque Peters (1990) visibiliza las denuncias hechas por las feministas contra las teorías de la victimización por su inaplicabilidad al estudio de los crímenes dirigidos contra mujeres (violación, malos tratos y violencia), considera que dicho enfoque de la victimología continúa mostrándose útil. De acuerdo a ello, afirma que la victimología actual debe concentrarse en las características de las víctimas que facilitan el delito por: atracción, proximidad, exposición; en suma, por un estilo de vida que aumenta el riesgo de victimización.

No fue entonces sino desde el feminismo que se visibilizaron las diferencias estructurales existentes entre las muertes intencionales de hombres y mujeres. En 1976 la académica Diana Russell, utilizó por primera vez el termino femicide (femicidio) cuando testificó sobre dicho crimen en el Tribunal Internacional de Crímenes contra Mujeres en 
Bruselas, y, en 1990 junto a Jane Caputi definió el femicidio como "el asesinato de mujeres realizado por hombres motivado por odio, desprecio, placer o un sentido de propiedad de las mujeres". No obstante, pese a los intentos de Russell por acuñar el término que perseguía denunciar la especificidad de los asesinatos generizados de las mujeres y en muchos casos sexualizados, encontró resistencias incluso al interior del movimiento feminista pues, desatendían este tipo de crímenes y, no los convirtieron en causa como lo había sido la violación y otras formas de violencia contra la mujer; situación que les mereció duras críticas por parte de las teóricas pioneras del femicidio.

Al respecto Jill Radford (2006) afirmaría que las discusiones feministas sobre el femicidio han estado limitadas en comparación con la discusión de la violencia sexual, la cual continúa siendo considerada como la forma más extrema de violencia contra la mujer; mientras que el femicidio aún no queda firmemente ubicado en la agenda feminista. Por su parte Diana Russell (2006) ha señalado que el femicidio ha sido tradicionalmente rechazado e ignorado por las feministas académicas, sólo una fracción de las autoras de libros y artículos sobre violencia contra las mujeres mencionan siquiera el problema de la matanza de mujeres, y son aún menos las que utilizan el término femicidio para describir estos asesinatos.

Este uso infrecuente del término femicidio por parte de las feministas, es decir, su negativa a develar las particularidades y especificidades sexistas y misóginas de este tipo de crímenes, de posicionar esta categoría en los diferentes espacios en los que hacen vida, así como, su renuencia a denunciar el fenómeno en los medios de comunicación a los que acuden y participan, según Russell (2006) es la razón más importante por la cual el femicidio permanece como la forma más desatendida de violencia contra las mujeres.

En el caso de América Latina el asesinato de mujeres por razones de género alcanzó altos índices de ocurrencia, se ha manifestado de forma sistemática y repetida, y se caracteriza por su particular crueldad y sexualización; sin embargo, los crímenes contra niñas y mujeres en 
Ciudad de Juárez, México, desde la década de los 90, alcanzaron gran relevancia en la agenda pública regional y mundial, por los numerosos casos, así como, por sus niveles de violencia, ensañamiento y crueldad. El caso de las "muertas de Ciudad Juárez" se convirtió en el paradigma de la violencia extrema hacia las mujeres, y el fallo de la corte interamericana de derechos humanos (CoIDH) en el año 2009 por el caso González y otras vs. México ("Campo Algodonero") donde se declaró la responsabilidad internacional del Estado mexicano en los homicidios por razones de género de tres de las ocho mujeres asesinadas, sentó las bases para la investigación, tipificación y sanción de estos delitos en la región.

Pero como señala Rocío González (2014) si bien Ciudad de Juárez se convirtió en el paradigma del femicidio en México, también se identificaron otros puntos geográficos en México con tasas de homicidios de mujeres similares a los de dicha ciudad fronteriza, y un patrón de violencia que incluía el asesinato de mujeres a manos de conocidos y extraños, precedidos, en ocasiones, por violencia sexual y/o física. Aunado a ello, y con base a la revisión de diversos informes sobre el femicidio en el país, señala la autora que se pudo concluir que durante el periodo 1985-2010 las mujeres fueron privadas de la vida sin importar la edad, alrededor del 42,5\% de los homicidios de mujeres se suscitaron en el espacio público, y destaca la brutalidad empleada por el victimario. Crímenes que según Toledo (2012) se distingue por actos de violencia sexual, mutilaciones en órganos sexuales o marcas que connotan odio.

Pese a ello, el femicidio como categoría de análisis fenomenológico y penal tardó mucho más en hacerse visible. Fue en el año 2006 con la edición en español de los libros Femicidio: La política del asesinato de las mujeres de Diana Russell y Jill Radford, así como, del libro Femicidio: una perspectiva global de Diana Russell y Roberta Harmes, 
realizada por Marcela Lagarde ${ }^{2}$, que este fenómeno -el asesinato de mujeres por misoginia o sexismo- se dio a conocer en la región bajo el término "feminicidio", lo cual abriría las compuertas para su posterior problematización, tipificación, cuantificación e investigación.

No obstante, la traducción de femicidio a feminicidio solo contribuyó a la generación de inexactitudes y confusiones respecto a la categoría femicidio. Rápidamente el termino feminicidio invadió el contexto latinoamericano, empezó a ser utilizado por las feministas académicas y los movimientos militantes de mujeres, los medios de comunicación, instituciones del Estado, organizaciones no gubernamentales o sin fines de lucro, así como, por distintos profesionales y activistas vinculados a los derechos de las mujeres, teniendo como consecuencia la despolitización y desgenerización del término femicidio inicialmente introducido y desarrollado. Es decir, dio paso a la compresión de la categoría "femicidio" simplemente como el asesinato de mujeres o la muerte violenta de mujeres, sin explicitar sus razones de género; por lo cual, se empezó a emplear el término "feminicidio" únicamente para aquellos que hacían referencia a los que tenían motivaciones sexistas. Este hecho ha tenido como consecuencia la contabilización errónea de los crímenes, la producción de estadísticas imprecisas, el tratamiento mediático inadecuado de los casos y la denominación diferenciada de la normativa jurídica en los distintos países de la región; hechos en su conjunto que han limitado la comprensión y actuación ante el fenómeno, situación que persiste aun en la actualidad.

\section{La tipificación del delito de femicidio en América Latina y en Argentina}

\footnotetext{
2 Marcela Lagarde quien coordinó y presentó la edición de estos textos, tradujo y sustituyó femicide (femicidio) por feminicidio, arguyendo que "en castellano femicidio es una voz homóloga a homicidio y sólo significa homicidio de mujeres", término que posteriormente se atribuiría.
} 
Los altos índices de ocurrencia del femicidio, su sistemática y repetida manifestación, así como, su particular crueldad y sexualización, motivaron a los movimientos feministas, investigadoras, activistas y población afectada (familiares y personas cercanas a las víctimas) a demandar a los Estados una efectiva, eficiente y oportuna prevención, atención y sanción de estos delitos. En este contexto, aunque México fue el primer país en el que se propuso la tipificación, Costa Rica se convirtió en el primer país en tipificar el femicidio en el año 2007. Posteriormente otros países de la región latinoamericana comenzarían a tipificar el delito, entre estos Guatemala (2008), Chile (2010), El Salvador (2011), Argentina (2012), Nicaragua (2012), México (2012), Bolivia (2013), Panamá (2013), Perú (2013), República Dominicana (2014), Ecuador (2014), Venezuela (2014), Colombia (2015), Paraguay (2016) y Uruguay (2017).

Esta tipificación del femicidio contribuyó a visibilizar las muertes de mujeres por razones de género, a problematizar la desigualdad y la violencia contra la mujer, y a generar un consenso social sobre la gravedad de estos crímenes; pero como señala González (2014), en la región la tipificación de estos delitos se caracteriza por su carácter simbólico, presentando alguno de los siguientes rasgos: 1) Se dispone de nulo o poco soporte financiero para su puesta en marcha. 2) No produce ningún cambio conductual de entre los que se propuso generar. 3) Los legisladores apoyan tales cambios legislativos aun cuando saben que no podrán ser puestos en práctica, no obstante, esto los coloca en una situación favorable frente a la opinión pública. 4) Transmite un mensaje de identificación con las víctimas, pero no tiene efectos materiales de cumplimiento.

Además, como bien expone González (2014), en varios de estos países cuando se realizó la aprobación o promulgación de la tipificación del femicidio/feminicidio, concurría algún proceso político-electoral; estos hallazgos sugieren una posible correlación entre el uso político del tema y la aprobación de aquellas reformas con miras a la obtención de réditos políticos entre la ciudadanía, pues se 
cree que siendo más duros contra los delincuentes se tendrán beneficios políticos. Es decir, en muchos casos esta tipificación se realiza sin que haya un convencimiento por parte del Estado de la gravedad de esta problemática, sin que exista un interés real por transformar esta situación, por salvaguardar la vida de las mujeres y que, en definitiva, solo buscan calmar la opinión pública con respecto a esta problemática a través de la creación de una falsa percepción de gestión institucional.

Por su parte en las legislaciones nacionales se denomina homicidio agravado (Argentina), femicidio (Chile, Costa Rica, Ecuador, Guatemala, Nicaragua, Panamá, Uruguay y Venezuela) o feminicidio (Bolivia, Colombia, El Salvador, México, Paraguay, Perú y República Dominicana); algunos de estos países incluyeron el tipo penal en el código penal, mientras que otros optaron por la incorporación del delito en leyes especiales y autónomas. Así mismo, algunos países tipificaron el delito con el propósito de visibilizar la particularidad y especificidad de este tipo de crímenes, mientras que otros lo harían como contra estímulo del impulso criminoso (Baratta, 2004), es decir, con el propósito de desincentivar la ocurrencia de estos delitos mediante la aplicación de penas ejemplificadoras; entre estos destacan: Bolivia, Nicaragua, Panamá, Paraguay y Venezuela con penas de hasta 30 años de cárcel, El Salvador y Costa Rica hasta 35 años, Republica Dominicana hasta 40 años, Colombia y Guatemala hasta 50 años, y Argentina, Chile y Perú donde las condenas pueden alcanzar cadena perpetua.

Sin embargo, la capacidad o función disuasoria de las penas ejemplarizantes han demostrado no ser efectivas, pues, "si la frecuencia criminal se mantiene, y más si ha aumentado, es claro que la pena máxima no tiene efecto preventivo disuasorio, fuera de que es obvio que no lo puede tener en los casos no tan raros de "femicidiosuicidio", a veces de brutal crueldad. Si bien es correcto seguir imponiendo esas penas, lo cierto es que el derecho penal llega tarde, pues las mujeres ya están muertas, y no parece razonable que el Estado 
se limite a recoger cadáveres e imponer penas" (Zaffaroni, 2017, sp). Además, según González (2014), la elevación de las penas por sí misma no conseguirá un efectivo procesamiento de tales delitos si no se acompaña de una mejora en el sistema de procuración de justicia penal para incrementar, por un lado, la certeza en la detección del responsable, la celeridad en la imposición del castigo, y la comunicación hacia la sociedad de la ilegitimidad de tales actos, por el otro.

En el caso específico de Argentina, el asesinato de una mujer por el hecho de ser mujer fue tipificado en el mes de diciembre del año 2012, cuando el Congreso de la Nación sancionó la Ley 26.791 que modifica el Código Penal e incorpora los incisos 11 y 12 al artículo 80, tipificando como homicidio agravado al que matare: "A una mujer cuando el hecho sea perpetrado por un hombre y mediare violencia de género" (Inciso $11^{\circ}$ ); "Con el propósito de causar sufrimiento a una persona con la que se mantiene o ha mantenido una relación en los términos del inciso $1^{\circ}$ " (Inciso $12^{\circ}$ ); tipificación que favorecería la posterior sistematización estadística de los casos de femicidio.

\section{Las técnicas de neutralización ante la ocurrencia del femicidio}

Pese a que el femicidio es una de las formas de violencia extrema contra la mujer más común y extendida en América Latina, y el delito ha sido progresivamente tipificado por los Estados de la región; la desigualdad por razones de género y los prejuicios a ella asociada contribuyen a que continúe siendo una de las formas de victimación de la mujer más invisibilizada, desestimada y justificada. Para los medios de comunicación, por ejemplo, "el homicidio de la mujer a golpes dentro del santo hogar familiar no produce pánico moral, se lo ignora. $\mathrm{Y}$ si alguno de estos homicidios tiene amplia cobertura periodística es por sus ribetes de morbosidad sexual" (Zaffaroni, 2012, p. 219).

En nuestras sociedades aunque la mayoría de los delitos cometidos contra la vida de los hombres y la propiedad son considerados como una inversión de los valores dominantes de una 
sociedad respetable que se somete a la ley (Cohen en Baratta, 2004), cuando se trata del femicidio, esta acción criminal y delictiva, no es concebida como una oposición a los valores dominantes; por el contrario, en un contexto donde la mujer ha sido históricamente subalternizada e inferiorizada, el acto femicida con frecuencia es interpretado como una reacción sancionatoria ante la transgresión de dichos valores dominantes por parte de la mujer. Es decir, el delito de femicidio y sus víctimas, se encuentran continuamente sujetas a diferentes Técnicas de neutralización.

Estas técnicas de neutralización pueden definirse según Sykes y Matza (2008) como los atenuantes de culpabilidad que se manifiestan como justificaciones o racionalizaciones del comportamiento desviado, delictivo o criminal, y persiguen evadir o disminuir la eficacia del control social. Son puestas en práctica previa o posteriormente a la comisión del crimen por parte de los victimarios, por los medios de comunicación, por la población en general, por el Estado en la figura de los operadores de justicia y el sistema penal; y según sus teóricos se dividen en cinco grandes tipos:

1) La negación de la responsabilidad, esta técnica se extiende más allá de alegar que los actos desviados son un "accidente", o incluso más allá de cualquier otra negación de la responsabilidad personal similar. Se caracteriza por recurrir a fuerzas ajenas, externas e inevitables, como causa e impulso de las acciones desviadas del delincuente, el cual según este criterio es arrastrado por las circunstancias. En el caso del delito de femicidio es común alegar el consumo de alcohol o estupefacientes, el padecimiento de patologías o trastornos mentales, la pérdida de la razón ante una exacerbada pasión, la experiencia de abandono materno, el haber sido víctima o espectador de violencia intrafamiliar en la infancia, entre otras.

2) La negación del daño, esta técnica se caracteriza por la evaluación moral del delito, es decir, entre actos que son en sí mismos 
"malos" y aquellos que son ilegales pero no inmorales. En este contexto las acciones del agresor son interpretadas como prohibidas, más no como inmorales o dañinas; además la "maldad" de un acto puede depender del hecho de si alguien sufrió o no por su desviación, lo cual puede ser interpretado de muchas maneras.

3) La negación de la víctima, en este caso, se parte de la idea de que el daño no es realmente un daño, por el contrario, se le considera una forma justa y necesaria de retribución o castigo. En este contexto el victimario es mitificado, convertido en vengador, en justiciero, restablecedor de la moral y los valores transgredidos; por su parte a la víctima se le transforma en culpable, inmoral o delincuente, en merecedora de la violencia y el crimen contra ella cometido. Negar la existencia de la víctima, entonces, al transformarla en una persona que merece sufrir un daño. En el caso del femicidio esto se hace evidente cuando se afirma que algo habrá hecho la víctima para ser objeto del crimen en cuestión, que se lo buscó, cuando se le culpabiliza del crimen por salir sola de noche, por ir de fiesta, por usar falda corta o vestidos y según este criterio "provocar a sus agresores", por consumir alcohol o drogas, por tener sexo, por "desobedecer" o confrontar a su pareja, por ser infiel, por ser lesbiana, travesti o transgénero, entre otras abundantes justificaciones.

4) La condena a quien condena, esta técnica implica la condena de quienes condenan, rechazan o cuestionan el crimen. En este caso el foco de atención es trasladado de los actos desviados (del delito y el agresor) hacia los motivos y el comportamiento de quienes desaprueban su violación de la ley. El delincuente y sus justificadores puede alegar que quienes lo van a condenar son hipócritas, desviados encubiertos, o que el rencor personal, el complejo y los resentimientos los incita a actuar así. La función de esta técnica consiste en dar vuelta o desviar las sanciones negativas que conlleva la violación de las normas, es 
decir, se desatiende al crimen y al agresor y se ataca a quienes interpelan al crimen y al criminal. En el caso del femicidio esto se expresa cuando la atención, los cuestionamientos y críticas son colocados en el movimiento feminista que denuncia y visibiliza el delito, en lugar de ser cuestionados, criticadas y confrontadas las actuaciones sexistas y misóginas de los agresores, así como, de las instituciones y procesos de socialización que favorecen la ocurrencia del crimen.

5) La apelación a lealtades superiores, en este caso se convoca el sacrificio, el apoyo, la fidelidad, la solidaridad y la defensa de grupos sociales más pequeños a los que pertenece el victimario, quien es defendido por su grupo social con independencia del delito cometido o la gravedad del hecho. Cuando se trata del femicidio es común ver la defensa y justificación del crimen y la responsabilización de la víctima por parte de familiares y amigos del agresor, así como, por parte del colectivo de hombres que se sienten identificados con este.

Estas técnicas de neutralización contribuyen a naturalizar, normalizar y cotidianizar el delito de femicidio, revictimizan a las víctimas, al mismo tiempo que, crean las condiciones para que esta forma extrema de violencia contra la mujer continúe ocurriendo en un escenario de permisividad social e impunidad penal.

\section{El femicidio en Argentina. Análisis estadístico para un abordaje cautelar}

Pese a la reiterada vulnerabilidad criminógena y victimológica de la mujer, los altos índices de ocurrencia del femicidio y la recurrente neutralización y justificación de este tipo de crímenes, este continúa siendo desatendido desde la criminología. En la actualidad el femicidio sigue siendo abordado, investigado y visibilizado casi exclusivamente por las académicas feministas, cuyo tratamiento siempre parte desde el análisis de la violencia por razones de género; no obstante, desde la 
criminología son muy pocas las aproximaciones a esta problemática, en su mayoría recientes y casi siempre orientados a evaluar la tipificación del delito, el tipo penal y sus agravantes.

Ante esta continua y sistemática desatención de la problemática del femicidio desde la criminología, consideramos que este debe ser abordado desde la perspectiva de la criminología cautelar -y militante-, la cual según Eugenio Raúl Zaffaroni (2012) debe responder al imperativo ético de salvar vidas humanas, para ello señala: 1) Debe estar atenta para analizar las condiciones sociales favorables a la creación mediática del mundo paranoico y desbaratar sus tentativas de instalación de las primeras manifestaciones organizas. B) Debe tomar muy en serio los daños reales del delito, es decir, la victimización y sus consecuencias, promoviendo en forma permanente la investigación de campo y del efecto que a este respecto tienen el propio poder punitivo y la criminología mediática. 3) Por último, debe investigar y proponer públicamente los medios más eficaces para la reducción de los anteriores.

En el caso específico que nos ocupa, para realizar este proceso de aproximación al femicidio en Argentina, recurrimos a las estadísticas oficiales disponibles en los informes del Registro Nacional de Femicidios ${ }^{3}$ de la Justicia Argentina correspondiente a los años 2014, 2015, 2016 y 2017 realizados por la Oficina de la Mujer de la Corte Suprema de Justicia de la Nación. Estas estadísticas victímales se

3 Tras la tipificación del delito en el año 2014, la Corte Suprema de Justicia de la Nación encomendó a la Oficina de la Mujer la elaboración del primer Registro Nacional de Femicidios de la Justicia Argentina, a fin de contar con información precisa, fiable, oportuna y pública sobre esta problemática; desde entonces se han sistematizado de forma oficial los asesinatos de mujeres motivados en el género ocurridos en este país. En este contexto el Registro Nacional de Femicidios de la Justicia Argentina destaca como uno de los pocos y más completos productos de sistematización en la materia de la región pues, además de Chile, Costa Rica y Perú, la mayoría de estos países no cuentan con información precisa, oportuna y pública sobre el femicidio; en la mayoría de los casos se limitan a presentar el número de víctimas anuales, sin ninguna información adicional que permita caracterizar y analizar el fenómeno. 
constituyen como el principal insumo para la puesta en práctica de un análisis cautelar del femicidio, específicamente mediante la caracterización del fenómeno, de las víctimas, los victimarios, las circunstancias y modalidades del crimen; lo cual favorece la identificación de los riesgos de femicidio, los medios que permitirán reducir la ocurrencia del delito, y por tanto, como lo señala Zaffaroni (2012) prevenir la violencia al proporcionar herramientas para la instalación de una criminología preventiva de Estado, con el objetivo de abatir sus índices de producción de cadáveres.

Ahora bien, de acuerdo a la información estadística oficial disponible correspondiente a los años 2014, 2015, 2016, 2017 y su abordaje desde la perspectiva de la criminología cautelar, es posible señalar que, durante dicho periodo se han contabilizado un total de 965 femicidios (de estos 10 califican como transfemicidio/travesticidio lo que equivale al 1\% de los casos, el 3,8\% del total de víctimas se encontraban en situación de vulnerabilidad o riesgo ${ }^{4}$ y al menos el $2,1 \%$ fueron víctimas de violencia sexual ${ }^{5}$ ), lo cual se traduce en un promedio de 241 femicidios al año y 20 femicidios al mes.

\footnotetext{
${ }^{4}$ Esta variable fue incluida por primera vez en el cuarto informe sobre el Registro Nacional de Femicidios de la Justicia Argentina correspondiente al año 2017 y comprende a las mujeres con discapacidad, mujeres embarazadas, mujeres migrantes internacionales, mujeres migrantes interprovincial e intraprovincial y mujeres en situación de prostitución.

5 Esta cifra pudiera ser más elevada debido a que la variable fue incluida por primera vez en el cuarto informe sobre el Registro Nacional de Femicidios correspondiente al año 2017, es decir, no se cuenta con información suficiente para realizar conclusiones y generalizaciones respecto a esta variable.
} 


\begin{tabular}{|c|c|c|c|c|c|}
\hline \multicolumn{6}{|c|}{ Gráfico 1. Femicidios en Argentina 2014-2017 } \\
\hline \multicolumn{2}{|c|}{ Año de ocurrencia de los femicidios } & 2014 & 2015 & 2016 & 2017 \\
\hline \multicolumn{2}{|c|}{ Número total de víctimas } & 225 & 235 & 254 & 251 \\
\hline \multicolumn{2}{|l|}{ Mujeres Trans o travestis } & & & $2 \%$ & $2 \%$ \\
\hline \multicolumn{2}{|c|}{ Mujeres en condición de vulnerabilidad } & & & & $14 \%$ \\
\hline \multicolumn{2}{|c|}{ Víctimas de violencia sexual } & & & & $8,3 \%$ \\
\hline Edad de las victimas & Entre 21 y 40 años & $42 \%$ & $43 \%$ & $49 \%$ & $60 \%$ \\
\hline \multicolumn{2}{|l|}{ Número total de imputados } & 228 & 236 & 258 & 259 \\
\hline Edad de los imputados & Entre 19 y 40 años & $49 \%$ & $54 \%$ & $58 \%$ & $75 \%$ \\
\hline \multirow{5}{*}{$\begin{array}{l}\text { Vínculo entre la víctima y el } \\
\text { imputado }\end{array}$} & Pareja & $57 \%$ & $58 \%$ & $61 \%$ & $59 \%$ \\
\hline & Familiar & $12 \%$ & $12 \%$ & $14 \%$ & $19 \%$ \\
\hline & Conocido & $6 \%$ & $17 \%$ & $11 \%$ & $18 \%$ \\
\hline & Extraño & $7 \%$ & $5 \%$ & $8 \%$ & $4 \%$ \\
\hline & Sin información & $18 \%$ & $8 \%$ & $6 \%$ & \\
\hline \multirow{4}{*}{ Lugar de ocurrencia } & Vivienda de la víctima & & & & $71 \%$ \\
\hline & Otra vivienda & & & & $9 \%$ \\
\hline & Espacio público & & & & $17 \%$ \\
\hline & Otro & & & & $3 \%$ \\
\hline \multirow{4}{*}{$\begin{array}{l}\text { Arma o modalidad } \\
\text { empleada }\end{array}$} & Arma de fuego & & & & $30,6 \%$ \\
\hline & Arma blanca & & & & $30,6 \%$ \\
\hline & Fuerza física & & & & $27 \%$ \\
\hline & Otros & & & & $11,5 \%$ \\
\hline \multicolumn{2}{|l|}{ Denuncias previas } & $13,3 \%$ & $19,5 \%$ & $24 \%$ & $25,4 \%$ \\
\hline \multirow{5}{*}{ Estado procesal } & En investigación & $27 \%$ & $51 \%$ & $47 \%$ & $62 \%$ \\
\hline & En juicio & $40 \%$ & $29 \%$ & $21 \%$ & $18 \%$ \\
\hline & Terminación del proceso & $18 \%$ & $14 \%$ & $22 \%$ & $15 \%$ \\
\hline & Sentencia condenatoria & $13 \%$ & $3 \%$ & $9 \%$ & $5 \%$ \\
\hline & Absolución o sobreseimiento & $2 \%$ & $3 \%$ & $1 \%$ & \\
\hline Provincia con más casos & Buenos Aires & $40,8 \%$ & $41,7 \%$ & $35,4 \%$ & $39 \%$ \\
\hline \multicolumn{2}{|c|}{ Menores de edad a cargo de la víctima } & 144 & 203 & 244 & 202 \\
\hline \multicolumn{2}{|l|}{ Femicidios vinculados } & & & & 22 \\
\hline
\end{tabular}

Fuente: Registro Nacional de Femicidios de la Justicia Argentina 2014-2017. 
Estas estadísticas ponen en evidencia que, en Argentina el femicidio no solo es una problemática constante, sino que, el riesgo de ser mujer en esta sociedad cada vez se hace más grande. Entre 2014 y 2016 el incremento de los femicidios fue de casi 10 puntos interanual, reduciéndose apenas 3 puntos durante 2017. Además, aunque este riesgo está presente en todo el país, las mujeres tienen más probabilidades de ser asesinadas en la Provincia de Buenos Aires, la cual concentra el 39,2\% del total de femicidios registrados entre los años 2014 y 2017.

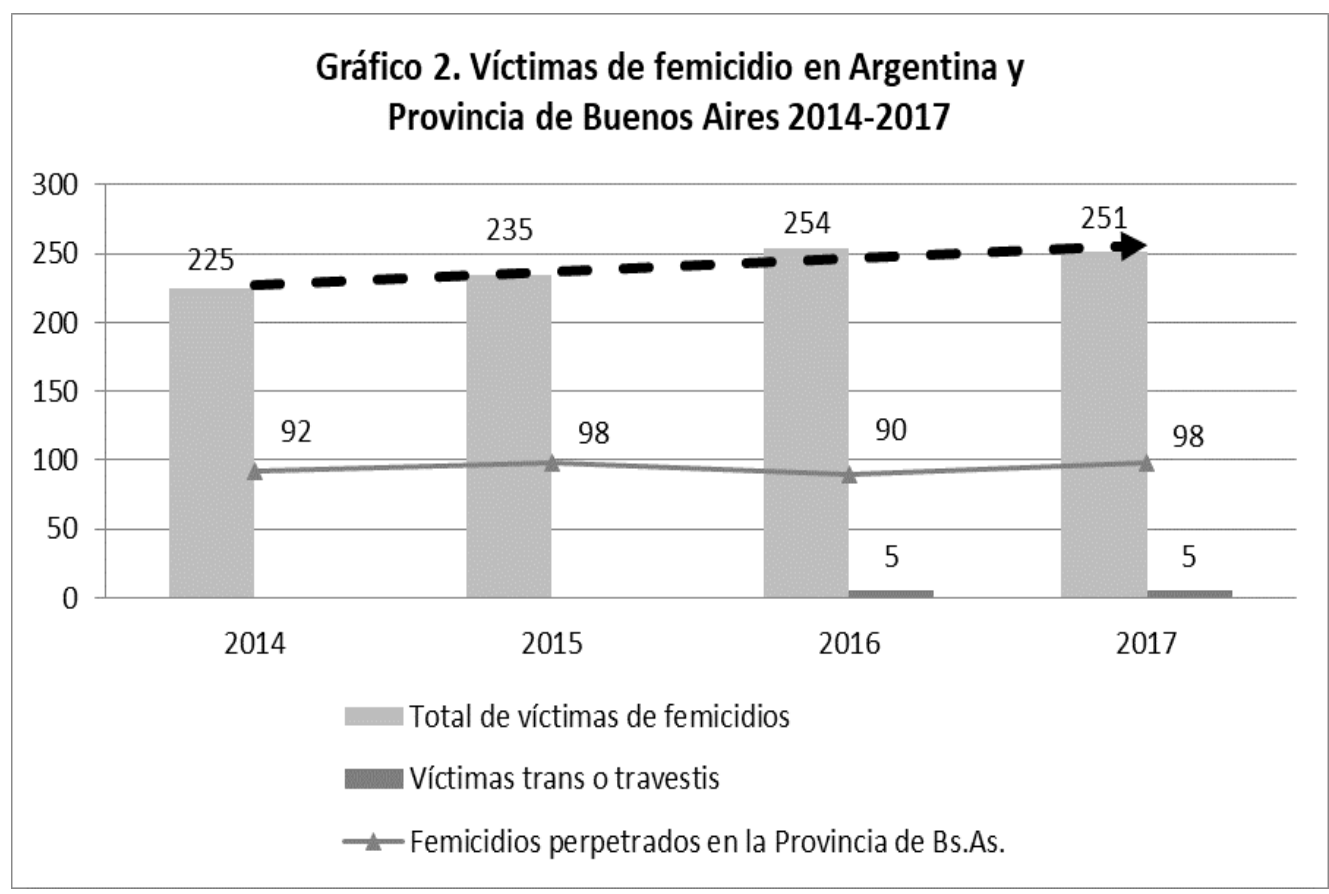

Fuente: Registro Nacional de Femicidios de la Justicia Argentina 2014-2017.

La disponibilidad de información sobre el grupo etario de las víctimas y los victimarios imputados también tributa a la comprensión y abordaje de este fenómeno. Si bien cualquier edad es una condición de riesgo para una mujer, incluso para las niñas, las adolescentes y las 
adultas mayores, la comisión de este tipo de delitos es predominante en las mujeres en edad reproductiva y por tanto de involucrarse en relaciones de pareja, es decir, con edades comprendidas en el rango de los 21 hasta los 40 años $^{6}$; esta situación confirma la tesis de la feminista Marta Dillon quien en una entrevista ha afirmado "la pareja heterosexual es un factor de riesgo para la vida de las mujeres". Además, el rango etario entre 19 y 40 años también es predominante entre los agresores, es decir, quienes están asesinando a las mujeres argentinas son hombres de su misma generación.

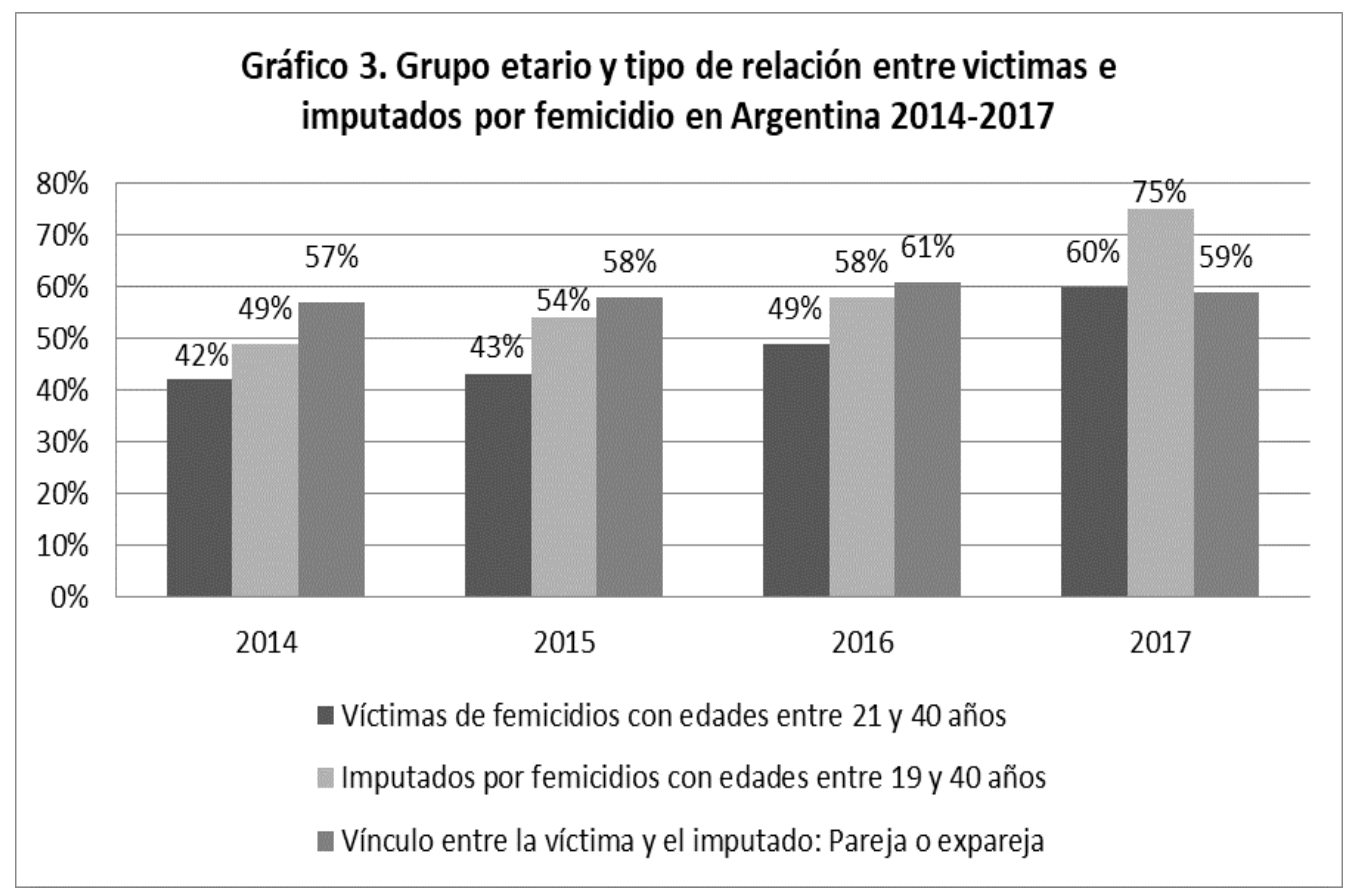

Fuente: Registro Nacional de Femicidios de la Justicia Argentina 2014-2017.

\footnotetext{
${ }^{6}$ Para el año 2017 el informe sobre el Registro Nacional de Femicidios de la Justicia Argentina modificó el rango de edad de las víctimas ampliando el grupo con más casos de 18 a 44 años. Para esta investigación se mantiene el rango etario de los informes anteriores a fin de garantizar una mayor homogeneidad en el análisis de los datos.
} 
En el 58,7\% de los casos los femicidas son aquellos hombres con los que la víctima tuvo o mantuvo algún tipo de relación sexo-afectiva (pareja o ex pareja), es decir, están durmiendo con el enemigo; así lo reflejan las estadísticas de femicidios correspondientes al año 2017, donde el $71 \%$ de los crímenes ocurrieron en la vivienda que la víctima compartía con su agresor o donde ella residía. De este modo es posible afirmar que para las mujeres el hogar no es un lugar seguro, por el contrario, es el espacio donde tiene más probabilidades de ser victimizadas. A estas cifras le siguen un $14,2 \%$ de femicidios cometidos por algún hombre perteneciente al grupo familiar (tipo de crímenes que comienzan a incrementarse año tras año), 13\% perpetrados por algún conocido y solo el $6 \%$ son cometidos por un extraño. También es importante destacar que en los crímenes contra las mujeres la violencia excesiva suele ser la norma, el 30,6\% de los femicidas empleó un arma de fuego para la comisión del delito, otro $30,6 \%$ hizo uso de arma blanca, el $27 \%$ recurrió a la fuerza física y el $11,5 \%$ apeló a otros recursos como el fuego u otros medios de combustión.

Otro dato que llama significativamente la atención es que la impunidad y la inacción institucional favorecen la ocurrencia e incremento de los femicidios. Las políticas e iniciativas de prevención de la violencia por razones de género enfatizan en la necesidad de denunciar la violencia machista, pero según los datos oficiales disponibles el 20,5\% de las victimas ya habían denunciado a su agresor (denuncias que además han aumentado 12 puntos en los últimos 4 años), sin embargo, no fueron protegidas o las medidas otorgadas no fueron efectivas pues, su vida terminó a manos de aquellos sobre quienes ya habían alertado estaban siendo violentadas o perseguidas.

Así mismo, si bien por el delito de femicidio entre 2014 y 2017 han sido imputadas 981 personas, estos se enfrentan a los retardos procesales y la burocratización del sistema penal. En lo que refiere al estado procesal de los femicidios ocurridos en este periodo el 46,7\% 
de los casos se encontraban en etapa de investigación, 27\% en etapa de juicio, en el 1,5\% de los casos hubo sobreseimiento, en el 17,2\% de los casos hubo extinción de la acción penal 7 , y solo en el 7,5\% de los 965 casos se ha obtenido una sentencia condenatoria para los responsables, incluso el número de sentencias entre 2014 y 2017 han disminuido.

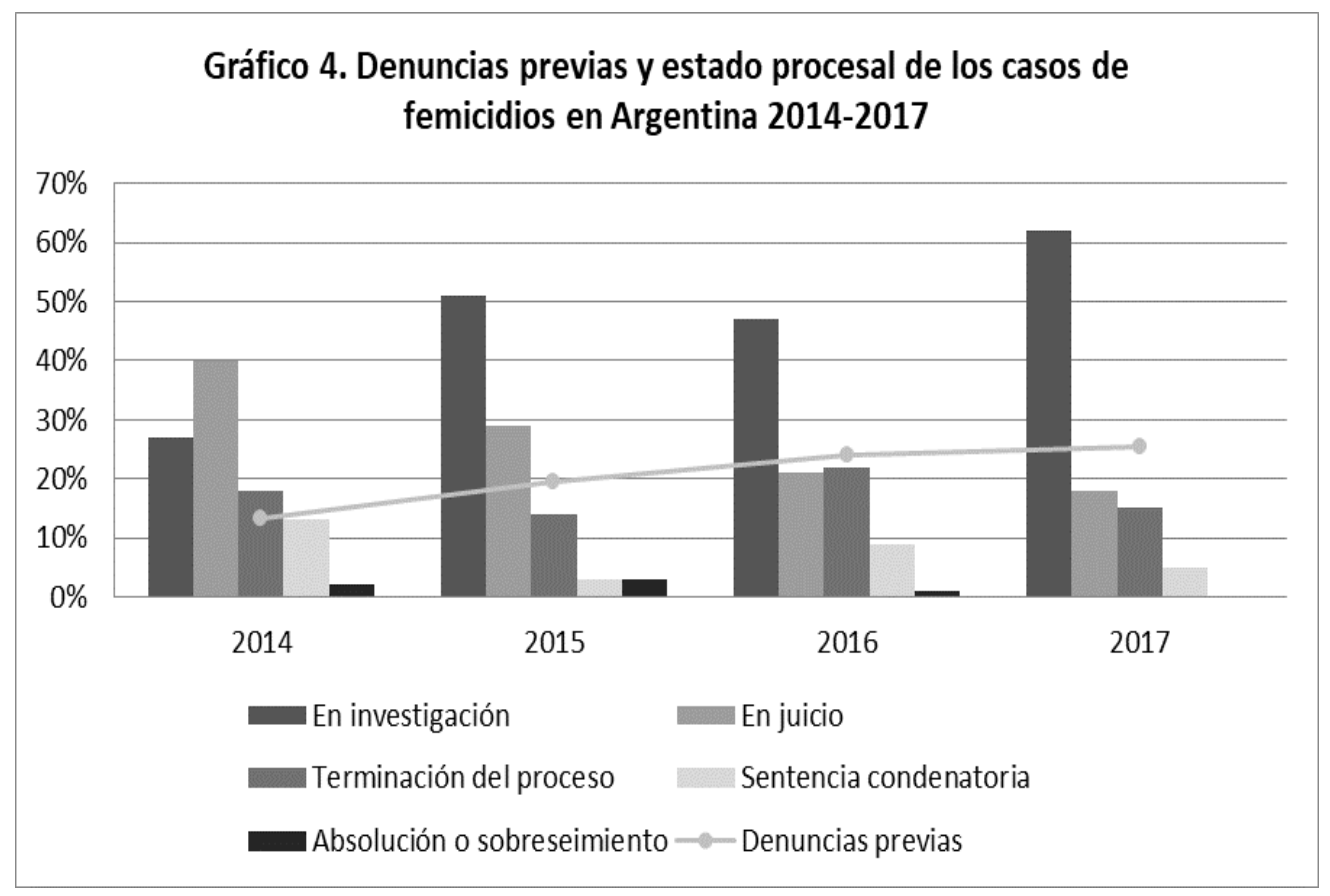

Fuente: Registro Nacional de Femicidios de la Justicia Argentina 2014-2017.

Además de ello, el femicidio es un crimen expansivo, en el cual no solo la mujer resulta victimizada, sino también de forma secundaria su colectividad y su familia. La información extraída del Registro Nacional de Femicidios de la Justicia Argentina permite conocer que

7 De acuerdo al Registro Nacional de Femicidios de la Justicia Argentina la categoría "Otra forma de terminación del proceso" hace referencia a la muerte del imputado -en su mayoría por suicidio-. 
793 niños, niñas y adolescentes que se encontraban a cargo de las víctimas han quedado desprotegidos como consecuencia de los femicidios registrados entre los años 2014 y 2017; a esto se suman los 22 femicidios vinculados ${ }^{8}$ registrados durante 2017.

\section{Conclusiones}

El término femicidio fue introducido en la década de los 70 por la académica Diana Russell, ante la necesidad de visibilizar, denunciar y estudiar los asesinatos de mujeres que tenían como motivación el sexismo y la misoginia en contextos de desigualdad por razones de género y relaciones de poder. En América Latina, aunque este fenómeno tiene décadas manifestándose, no fue sino en la última década que comenzó a ser estudiado y tipificado en los códigos penales y legislaciones especiales de los países; pese a ello, este delito continúa siendo desatendido por la criminología, pero también justificado y naturalizado por sus perpetradores, la población en general, los medios de comunicación, e incluso por el sistema penal.

En el caso específico de Argentina este delito fue tipificado en el año 2012 bajo la figura de homicidio agravado, lo que posteriormente propicio la creación del Registro Nacional de Femicidios de la Justicia Argentina, el cual comenzó a sistematizar los casos de femicidio en el año 2014. Fue entonces ante la disponibilidad de esta información oficial y la ausencia de investigaciones de la misma naturaleza, que nos propusimos analizar desde la perspectiva de la criminología cautelar el femicidio en Argentina entre los años 2014 y 2017.

\footnotetext{
${ }^{8}$ Es importante destacar que por primera vez el informe sobre el Registro Nacional de Femicidios de la Justicia Argentina correspondiente al año 2017 incorporó en sus estadísticas femicidios vinculados o por interposición en la línea de fuego; esto comprende el homicidio de una o varias personas (niñas, niños, adolescentes, mujeres, varones, trans, travesti) con el propósito de causar daño y sufrimiento a la mujer objetivo, o el homicidio de una o varias personas cuando intentaban evitar la comisión del femicidio. También llama significativamente la atención que la totalidad de las víctimas de femicidios vinculados para 2017 fueron mujeres trans o travestis.
} 
Este proceso investigativo nos permitió hallar que durante el referido periodo han sido victimizadas 965 mujeres, con edades entre los $21 \mathrm{y}$ 40 años y, en al menos el 58,7\% de los casos fueron asesinadas por sus parejas o ex parejas, quienes además pertenecen a su mismo grupo etario. El 71\% fue victimizada en la vivienda en la que residía sola o con el agresor, y para la comisión de este tipo de delitos es común el empleo de diversas armas y modalidades. Así mismo, el 39\% de los crímenes ocurrieron en la Provincia de Buenos Aires, y el 20,5\% de las victimas ya había denunciado a su agresor, pero no recibió la atención y protección necesaria por parte de las autoridades de competencia.

Esta información permite construir un perfil muy claro de la víctima y del agresor, al mismo tiempo que proporciona información de calidad para el diseño de políticas públicas específicas para su prevención; por lo cual al respecto es posible recomendar grosso modo:

1) Realizar un abordaje integral del fenómeno en articulación con los diferentes actores e instituciones sociales involucradas desde una perspectiva transdisciplinar.

2) Superar el enfoque femenil de las políticas dirigidas a prevenir y erradicar la violencia por razones de género, entendiendo que este tipo de violencia no es solo un asunto de mujeres, sino de los hombres que la perpetran. En este caso las iniciativas deben enfatizar en informar y sensibilizar a las mujeres y hombres en edad reproductiva en el contexto de relaciones de pareja; población que detenta los mayores índices de riesgo de convertirse en victimarios y victimas de femicidio respectivamente.

3) Destinar mayores recursos económicos para las políticas públicas de prevención de la violencia contra las mujeres.

4) Mejorar los procesos de información, atención y protección de las víctimas de violencia de género por parte de los operadores de justicia. 
5) Trascender la judicialización como mecanismo único de atención de la violencia por razones de género, aunado al monitoreo de los procesos de aplicación de las leyes para prevenir y erradicar el femicidio.

6) Desarrollar programas orientados a rehabilitar y trabajar con hombres agresores reales o potenciales.

7) Profundizar y fortalecer los procesos de formación y sensibilización en materia de violencia contra la mujer y femicidios de los operadores de justicia.

8) Diseñar un modelo de protocolo para el abordaje mediático de los casos de femicidios, a fin de sensibilizar a los profesionales de la comunicación para evitar la justificación de los crímenes y la revictimización de las víctimas.

\section{Referencias bibliográficas}

Baratta, A. (2004). Criminología crítica y critica del derecho penal. Introducción a la sociología jurídico-penal. Buenos aires, Argentina: Siglo XXI Editores.

Corte Suprema de la Justicia de la Nación. (2014-2016) Registro Nacional de Femicidios de la Justicia Argentina. Recuperado de: https://goo.gl/bdALFG

Corte Suprema de la Justicia de la Nación. (2017) Registro Nacional de Femicidios de la Justicia Argentina. Recuperado de: https://goo.gl/tcWPCi

Cuarezma, S. (1996). La Victimología. En Estudios Básicos de Derechos Humanos Tomo V. (pp. 295 - 317). San José, Costa Rica: Instituto Interamericano de Derechos Humanos.

González, R. (2014). Cuando el derecho penal no basta. Reflexiones en torno a la tipificación del feminicidio en México. Alegatos, (87), pp. 271-308.

La pareja heterosexual es un riesgo para la vida de las mujeres. (03 de junio 2018). Infobae. Recuperado de https://goo.gl/Zif6uR 
Ley 26791 y Decreto 2396/2012. Código Penal de Argentina. Recuperado de: https://goo.gl/f66Unm

Peters, T. (1988). Consideraciones teóricas sobre la victimología. Eguzkilore. Cuaderno del Instituto Vasco de Criminología, (2), pp. 107-133.

Peters, T. (1990) Criminología y victimología. En A. Beristain. y JL. de la Cuesta. (Ed.), Victimología: VIII Cursos de Verano en San Sebastián (pp. 97-103). San Sebastián, España: Universidad del País Vasco.

Russell, D. y Radford, J. (2006) Feminicidio. La politica del asesinato de las mujeres. México D.F., México: Centro de investigaciones interdisciplinarias en Ciencias y Humanidades Universidad Nacional Autónoma de México.

Sykes, M. y Matza, G. (2008). Técnicas de neutralización: Una teoría de la delincuencia. Caderno CRH, 21(52), pp. 163-171.

Toledo, P. (2012) La tipificación del femicidio/feminicidio en países latinoamericanos. Antecedentes y primeras sentencias (1999-2012). Barcelona, España: Universidad Autónoma de Barcelona.

Una falla del pensamiento feminista es creer que la violencia de género es un problema de hombres y mujeres. (23 de agosto 2017). Conclusión. Recuperado de https://goo.gl/n2DYyh

Zaffaroni, E. (2012). La cuestión criminal. Buenos Aires, Argentina: Editorial Planeta.

Zaffaroni, R. (18 de mayo 2017) Femicidio. Página 12. Recuperado de https://goo.gl/CKTtj2 